\title{
Development and validation of the Child Three-Factor Eating Questionnaire (CTFEQr 17)
}

\author{
Eleanor J Bryant ${ }^{1, *}$, David Thivel ${ }^{2}$, Jean-Philippe Chaput $^{3}$, Vicky Drapeau ${ }^{4}$, \\ John E Blundell ${ }^{5}$ and Neil A King ${ }^{6}$ \\ 'Division of Psychology, Faculty of Social Sciences, University of Bradford, Great Horton Road, Bradford, West \\ Yorkshire, BD7 1DP, UK: ${ }^{2}$ Clermont Auvergne University, EA 3533, Laboratory of the Metabolic Adaptations to \\ Exercise under Physiological and Pathological Conditions (AME2P), CRNH-Auvergne, Clermont-Ferrand, France: \\ ${ }^{3}$ Healthy Active Living and Obesity Research Group, Children's Hospital of Eastern Ontario Research Institute, \\ Ottawa, Ontario, Canada: ${ }^{4}$ Department of Physical Education, Faculty of Education, Université Laval, Québec City,

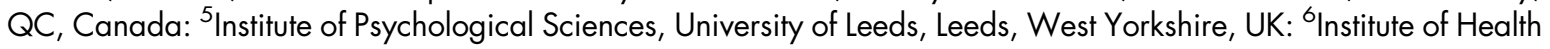 \\ Biomedical Innovation, Queensland University of Technology, Brisbane, Queensland, Australia
}

Submitted 14 December 2017: Final revision received 26 February 2018: Accepted 5 April 2018: First published online 15 May 2018

\begin{abstract}
Objective: To develop and validate a child and adolescent version of the ThreeFactor Eating Questionnaire (CTFEQr17) and to assess its psychometric properties and factor structure. We also examined associations between the CTFEQr17 and BMI and food preferences.

Design: A two-phase approach was utilized, employing both qualitative and quantitative methodologies.

Setting: Primary and secondary schools, UK.

Subjects: In phase 1, seventy-six children (thirty-nine boys; mean age $12 \cdot 3$ (SD 1.4) years) were interviewed to ascertain their understanding of the original TFEQr21 and to develop accessible and understandable items to create the CTFEQr17. In phase 2, 433 children (230 boys; mean age 12.0 (SD 1.7) years) completed the CTFEQr17 and a food preference questionnaire, a sub-sample ( $n$ 253; 131 boys) had their height and weight measured, and forty-five children (twenty-three boys) were interviewed to determine their understanding of the CTFEQr17.

Results: The CTFEQr17 showed good internal consistency (Cronbach's $\alpha=0 \cdot 85$ ) and the three-factor structure was retained: cognitive restraint (CR), uncontrolled eating (UE) and emotional eating (EE). Qualitative data demonstrated a high level of understanding of the questionnaire (95\%). High CR was found to be significantly associated with a higher body weight, BMI and BMI percentile. High UE and EE scores were related to a preference for high-fat savoury and high-fat sweet foods. The relationships between CTFEQr17, anthropometry and food preferences were stronger for girls than boys.

Conclusions: The CTFEQr17 is a psychometrically sound questionnaire for use in children and adolescents, and associated with anthropometric and food preference measures.
\end{abstract}

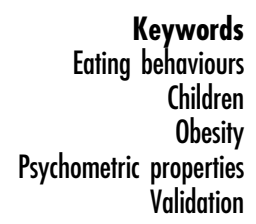

The prevalence of obesity in children and adolescents has reached epidemic proportions worldwide and is associated with many co-morbidities ${ }^{(1-3)}$. Paediatric obesity is closely linked to the so-called 'obesogenic' environment where a myriad of factors is conducive to eating too much and not moving enough, thereby promoting weight gain and ultimately overweight and obesity ${ }^{(4,5)}$. Among the many factors that explain the susceptibility to gain weight, a better understanding of the link between eating behaviours and weight gain is of crucial importance to overcome the rising rates of obesity.
Obesity interventions have to consider individuals' eating behaviours, especially those that have been associated with obesity and weight gain ${ }^{(6,7)}$. For example, dietary restriction can promote overeating in dietary restrained adolescents having disinhibited eating behaviour ${ }^{(8)}$. Additionally, adolescents with high restrained eating behaviour scores are more likely to gain weight over time $^{(9)}$. Properly assessing eating behaviours of children and adolescents remains challenging, however.

In 1985, Stunkard \& Messick developed the ThreeFactor Eating Questionnaire (TFEQ) as a self-reported 
scale based on the restraint ${ }^{(10)}$ and latent obesity ${ }^{(11)}$ theories, to assess dietary restraint (restriction of food intake to control weight), disinhibition (tendency to overeat opportunistically) and hunger (responsiveness to internal hunger sensations). While this initial version of the TFEQ developed in adults has been shown to clearly link eating behaviours with weight gain and weight-loss success $^{(12-15)}$, it has been recently revised into a shorter twenty-one-item version (TFEQr21) focusing on restraint, uncontrolled eating and emotional eating ${ }^{(13)}$. In this last version, although the restraint dimension remains unchanged, uncontrolled eating refers to eating in response to food palatability and the likelihood to overconsume, and emotional eating represents the process to eat in response to negative moods ${ }^{(13)}$.

Despite a significant body of literature regarding the utility of the TFEQ in adults ${ }^{(13-18)}$, the validity of this TFEQr21 remains to be tested among children and adolescents. Martín-García et al. ${ }^{(19)}$ recently reported a strong association between body composition and cognitive restraint in 7-17-year-old Spanish youth using a modified version of the Spanish adult TFEQ. These results highlight the usefulness of the TFEQr21 in children, but only in a limited population. It thus remains important to develop and validate a specific version of the English TFEQr21 for children and adolescents to better characterize their eating behaviour traits and evaluate the impact of obesity interventions in this population.

The objective of the present study was to develop an adapted-version of the adult TFEQr21 to be used among children and adolescents (CTFEQr17) and to assess its psychometric properties and factor structure. We also examined the associations between the CTFEQr17 and BMI and food preferences as a secondary objective.

\section{Methods}

The process of developing and validating the CTFEQr17 comprised two phases: the CTFEQr17 was developed in phase 1 and validated in phase 2. Each phase is detailed below.

\section{Phase 1: Development of the CTFEQr17}

\section{Participants}

A sample of seventy-six children (thirty-nine boys and thirty-seven girls) recruited between 2013 and 2014 from primary and secondary schools in North and West Yorkshire, UK were interviewed to determine their understanding of the original TFEQr2 $1^{(13)}$ items and to develop the wording of the CTFEQr17 (mean age: 12.3 (SD 1.4) years; mean BMI: $19 \cdot 1$ (SD 2.5) kg/m² ; mean BMI percentile: 59.4 (SD 25.8)). All children, their guardians and the school gave informed consent for participation. Children who had any known eating disorders or eating issues, or who had difficulties with reading were excluded from participation
( $n$ 5). These children were identified by parents and/or teachers. The project gained full ethical approval from the University of Bradford Ethics Committee.

\section{Qualitative design}

The children took part in one-to-one structured interviews with the researchers. The child was presented with the adult version of the TFEQr21 ${ }^{(13)}$ and was asked whether he/she understood each item, if he/she understood how to respond to each question and to put each item into his/ her own words. The interviews allowed the researchers to determine the children's understanding of each item. Sample percentages were calculated for correct understanding of each item. In addition, the wording the children used to describe each item was then used to develop the CTFEQr17. This was achieved by recording the most frequently used words and phrases for each item and adopting these words, and phrases, in the new items. The interviews were audio-recorded and transcribed for analysis. Two researchers independently analysed the children's responses to try to reach a subjective consensus on the child responses.

\section{Anthropometric measurements}

Body weight was assessed using a Seca 877 weighing scale and was measured to the nearest $0 \cdot 1 \mathrm{~kg}$. Children wore loose and lightweight shorts and a T-shirt to be weighed. Height was measured while the child was barefoot, using a Leicester stadiometer, and was measured to the nearest $0 \cdot 1 \mathrm{~cm}$. BMI was calculated as [weight $(\mathrm{kg})$ ]/ [height $(\mathrm{m})]^{2}$. BMI percentiles were calculated using the $\mathrm{WHO}^{(20)}$ criteria based on age and sex.

\section{Phase 2: Validation of the CTFEQr17}

A sample of 433 children (230 boys; mean age: $12 \cdot 0$ (sD $1.7)$ years; mean BMI: $19.7(\mathrm{sD} 4.5) \mathrm{kg} / \mathrm{m}^{2}$; mean BMI percentile: 57.6 (SD 30.9)) from primary and secondary schools in West Yorkshire and Lancashire, UK were recruited between 2016 and 2017. A sub-sample of fortyfive children (twenty-three boys and twenty-two girls) took part in interviews to confirm their understanding of the CTFEQr17. All children, their guardians and the school gave informed consent for participation. Children who had any known eating disorders or eating issues, or who had difficulties with reading were excluded from participation ( $n$ 23). The project gained full ethical approval from the University of Bradford Ethics Committee.

\section{Validation design}

Children were asked to self-complete the CTFEQr17 and an adapted paper-based Leeds Food Preference Questionnaire (LFPQ), suitable for use with children ${ }^{(21)}$. The LFPQ consists of a list of common UK foods (e.g. crisps, strawberries, yoghurt, biscuits) and the child was asked to indicate if he/ she would like to consume these foods. Responses were then coded and summed into preference for high-protein 
(eight items), high-fat (eight items), high-carbohydrate (eight items) and low-energy foods (eight items). Mean taste preference scores were also calculated for low-fat savoury foods (LFSA: twelve items), low-fat sweet foods (LFSW: five items), high-fat savoury foods (HFSA: eight items) and high-fat sweet foods (HFSW: seven items).

\section{Anthropometric measurements}

A sub-sample of children had their height and weight measured (131 boys and 122 girls). Anthropometric measures were taken using the same procedure as in phase 1 .

\section{Qualitative design}

The children took part in structured one-to-one interviews with a researcher. They were presented with the CTFEQr17 and asked if they understood each item, understood how to respond to each question and asked to elaborate on what they thought each item meant, to confirm their understanding. Each interview lasted approximately $20 \mathrm{~min}$. Interviews were audio-recorded and transcribed for analysis.

\section{Statistical analysis}

We calculated that a total sample of 338 would be sufficient (power $\approx 0 \cdot 90$, effect size $=0 \cdot 25$, probability level $=0 \cdot 05$ ) to run the planned analysis. An exploratory, varimax rotation, principal components factor analysis was carried out to determine the factor structure of the CTFEQr17. An item analysis was also conducted to confirm the internal consistency, item-convergent and item-divergent validity of the CTFEQr17 items. Bivariate correlations explored relationships between age and CTFEQr17 factors by sex, and ANOVA was used to determine differences between sex and age groups (7-10 years and 11-15 years) on each CTFEQr17 factor. Partial correlations, controlling for age, were used to examine relationships between CTFEQr17 factors and anthropometric measurements. Partial correlations, controlling for age and BMI, were also used to explore relationships between CTFEQr17 factors and food and taste preferences. Only correlations above 0.20 are reported. Groups were formed using a median split on cognitive restraint (CR), uncontrolled eating (UE) and emotional eating (EE) scale scores to create low and high CR groups (LCR and HCR), low and high UE groups (LUE and HUE) and low and high EE groups (LEE and HEE). ANCOVA was used to analyse differences in anthropometric measures (controlling for age) and in food and taste preferences (controlling for age and BMI) by sex and eating behaviour groupings. Effect size was measured through $\eta^{2}$. For the qualitative data, the children's comments were used to determine their level of understanding of each item of the CTFEQr17 and percentages of the correctly understood items were calculated. Understanding of items between phase 1 and 2 was examined using $t$ tests. The statistical software package IBM SPSS Statistics version 22 was used to conduct the analyses and the level of statistical significance was set at $P<0.05$ for all analyses.

\section{Results}

\section{Phase 1: Development of the CTFEQr17}

The qualitative data from the interviews with children revealed that there were a number of items in the TFEQr $21^{(13)}$ that the children had difficulty in understanding, particularly items 9, 17 and 21 . To develop a more understandable questionnaire, these items were reworded, using the children's own language, as ascertained from the interviews (see Appendix for the CTFEQr17). In addition, the children also deemed the response format of the TFEQr21 unclear and too complex; thus, the response format of the CTFEQr17 was altered to read 'totally true', 'mostly true' 'mostly false' and 'totally false', again utilizing the phraseology of the children from the interviews.

\section{Phase 2: Validation of the CTFEQr17}

Structure and internal consistency of the CTFEQr17 The data met the assumptions for factor analysis, with the Kaiser-Meyer-Olkin measure of sampling adequacy index $=0.87$ and a significant Bartlett's test of sphericity $\left(\chi^{2}=2706.45, P<0.001\right)$, indicating that the correlations between items were sufficiently large for a principal component analysis. A varimax rotation principal component analysis initially revealed four factors with eigenvalue $>1$, which in combination explained $51.6 \%$ of the variance. The factors of UE (items 3, 6, 8, 9, 12, 13, 15, 19 and 20) and $\mathrm{EE}$ (items 2, 4, 7, 10, 14 and 16) were retained as in the original TFEQr21. However, CR loaded into two factors: CR1 (items 1, 5 and 11) and CR2 (items 17, 18 and 21). The items in CR1 are related to current food restriction behaviour, whereas CR2 is related to more prospective food restriction behaviours. However, following the removal of weak items due to low inter-item and item-tototal correlations and Cronbach's $\alpha$ increasing after item removal $(17,18,19$ and 21), a three-factor structure was revealed, which explained $53.5 \%$ of the variance. The factors of UE (items 3, 6, 8, 9, 12, 13, 15 and 20), EE (items 2, 4, 7, 10, 14 and 16) and CR (items 1, 5 and 11) were retained to create a CTFEQr17.

Following an analysis of internal consistency, the CTFEQr17 had a Cronbach's $\alpha$ of $0 \cdot 85$, with the factors of UE $(\alpha=0.85)$ and EE $(\alpha=0.83)$ showing similarly high scores. The factor of CR had Cronbach's $\alpha=0 \cdot 67$, which, although lower than UE and EE, was deemed adequate. The item analysis also revealed that the factors had adequate to good inter-item correlations for CR $(r=0 \cdot 38$ $0 \cdot 47)$, UE $(r=0 \cdot 32-0.58)$ and EE $(r=0.36-0 \cdot 59)$, showing that the items within each scale correlated with one another. The corrected item-to-total correlations were good; CR $(r=0.46-0.52)$, UE $(r=0.53-0.63)$ and EE 
( $r=0 \cdot 55-0 \cdot 70)$, with the items correlating most strongly with their respective factors, supporting item-discriminant and convergent validity. The factor of UE correlated significantly with EE $(r=0 \cdot 47, P<0 \cdot 001)$ only (Table 1$)$.

\section{Children's understanding of the items}

The qualitative aspect of the analysis, concerning the children's understanding of the questionnaire items, revealed a very good level of understanding of the CTFEQr17. More specifically, in comparison to the original
TFEQr21, all items of the CTFEQr17 were more understandable (mean understanding of $95 \% v .81 \%$ for the original TFEQr21; see Fig. 1), where items 2, 9, 10, 11 and 12 were significantly more understood $(P<0.05)$ compared with the original TFEQr21.

\section{Participant characteristics and CTFEQr17}

For both boys and girls, UE correlated negatively with age $(r=-0.32, \quad P<0.001$ and $r=-0.25, P=0.001$, respectively). CR correlated negatively with age for girls only

Table 1 Rotated factor structure loading of the new Child Three-Factor Eating Questionnaire (CTFEQr17)

\begin{tabular}{|c|c|c|c|c|}
\hline & $\begin{array}{l}\text { Uncontrolled } \\
\text { eating }\end{array}$ & $\begin{array}{l}\text { Emotional } \\
\text { eating }\end{array}$ & $\begin{array}{l}\text { Cognitive } \\
\text { restraint (1) }\end{array}$ & Communalities \\
\hline $\begin{array}{l}\text { 12. When I smell or see my favourite food, I find it hard to stop myself from eating } \\
\text { it, even if I've just finished a meal. }\end{array}$ & 0.73 & & & 0.56 \\
\hline $\begin{array}{l}\text { 8. I often get so hungry that I feel like I could eat loads of food without getting } \\
\text { full. }\end{array}$ & 0.72 & & & 0.53 \\
\hline $\begin{array}{l}\text { 15. When I see something that looks delicious, I get so hungry that I have to eat } \\
\text { it right away. }\end{array}$ & 0.70 & & & 0.53 \\
\hline 3. Sometimes when I start eating, it seems I can't stop. & 0.69 & & & 0.52 \\
\hline 6. When I am next to someone who is eating, I also feel like eating. & 0.67 & & & 0.51 \\
\hline 13. I'm always hungry enough to eat at any time. & 0.66 & & & 0.49 \\
\hline 20. How often do you feel hungry? & 0.63 & & & 0.47 \\
\hline $\begin{array}{l}\text { 9. When I am hungry, I feel like to have to eat all of the food on my plate in one } \\
\text { go, without stopping. }\end{array}$ & 0.61 & & & 0.45 \\
\hline 16. When I feel really upset, I want to eat. & & 0.81 & & 0.67 \\
\hline 14. If I feel nervous, I try to calm myself down by eating. & & 0.73 & & 0.60 \\
\hline 2. I start to eat when I feel worried. & & 0.72 & & 0.55 \\
\hline 7. When I feel angry, I need to eat. & & 0.68 & & 0.49 \\
\hline 4. When I am sad, I usually eat too much. & & 0.66 & & 0.49 \\
\hline 10. When I feel lonely, I make myself feel better by eating. & & 0.65 & & 0.51 \\
\hline 1. I eat small portions of food to help control my weight. & & & 0.80 & 0.64 \\
\hline 11. I eat less than I want at meal times to stop myself putting on weight. & & & 0.78 & 0.61 \\
\hline 5. I don't eat some kinds of food because they can make me fat. & & & 0.72 & 0.55 \\
\hline Explained variance (\%) & $31 \cdot 20$ & $12 \cdot 75$ & 9.54 & \\
\hline Cumulative variance (\%) & $31 \cdot 20$ & 43.95 & 53.45 & \\
\hline
\end{tabular}

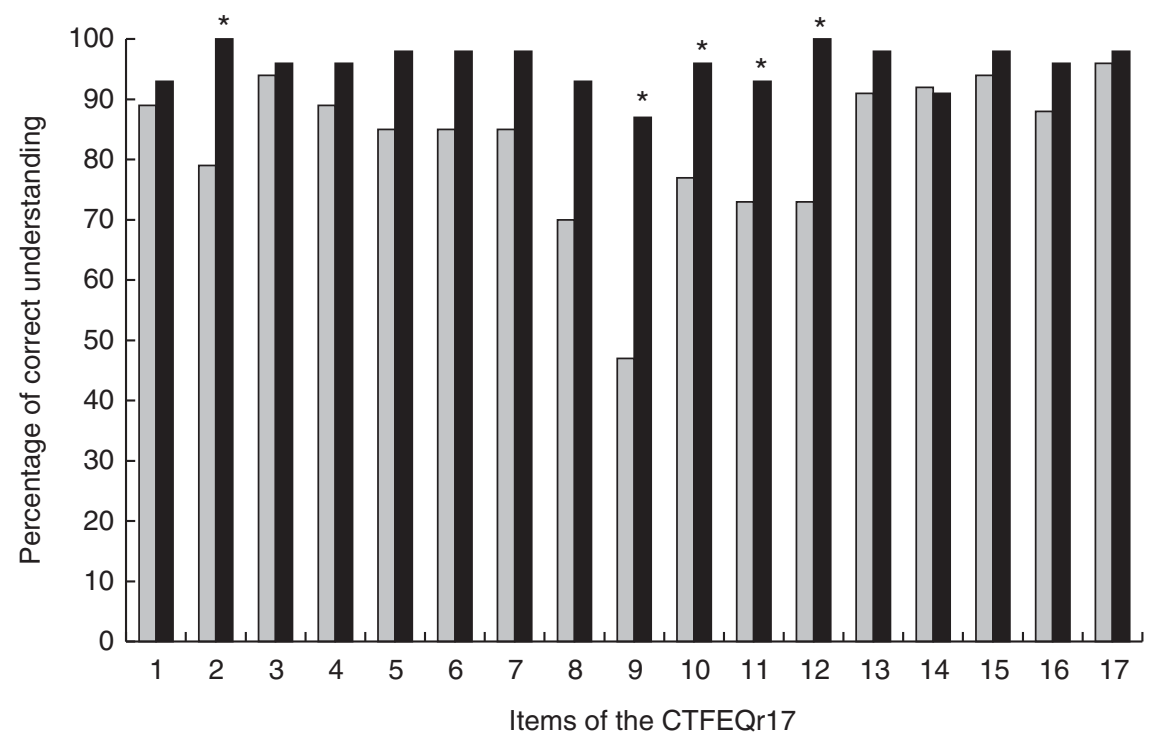

Fig. 1 Comparison of percentage correct understanding of items between the original Three-Factor Eating Questionnaire (TFEQr21; $\square$ ) and the new Child Three-Factor Eating Questionnaire (CTFEQr17; $\square$ ) among a sub-sample of forty-five children and adolescents (twenty-three boys) recruited from primary and secondary schools in West Yorkshire and Lancashire, UK, in 20162017. *Understanding of the CTFEQr17 item was significantly higher than for the original TFEQr21 item $(P<0.05)$ 
Table 2 Factor scores on the new Child Three-Factor Eating Questionnaire (CTFEQr17), by age group and sex, among a sample of 433 children and adolescents (230 boys) recruited from primary and secondary schools in West Yorkshire and Lancashire, UK, 2016-2017

\begin{tabular}{|c|c|c|c|c|c|c|c|c|}
\hline & \multicolumn{4}{|c|}{ Primary school (7-10 years) } & \multicolumn{4}{|c|}{ Secondary school (11-15 years) } \\
\hline & \multicolumn{2}{|c|}{ Boys ( $n$ 46) } & \multicolumn{2}{|c|}{ Girls ( $n$ 39) } & \multicolumn{2}{|c|}{ Boys ( $n$ 184) } & \multicolumn{2}{|c|}{ Girls ( $n$ 174) } \\
\hline & Mean & SD & Mean & SD & Mean & SD & Mean & SD \\
\hline $\mathrm{CR}$ & $2.38 \dagger$ & 0.78 & $2.52 \dagger$ & 0.81 & $2 \cdot 37$ & 0.72 & $2 \cdot 16$ & 0.66 \\
\hline UE & $2 \cdot 88^{*}, \dagger$ & 0.87 & $2.50 \dagger$ & 0.88 & $2 \cdot 25^{\star}$ & 0.59 & $2 \cdot 11$ & 0.64 \\
\hline $\mathrm{EE}$ & 1.52 & 0.61 & 1.65 & 0.65 & 1.48 & 0.54 & 1.58 & 0.63 \\
\hline
\end{tabular}

$\mathrm{CR}$, cognitive restraint; UE, uncontrolled eating; EE, emotional eating.

${ }^{*}$ Boys had a significantly higher mean UE score compared with girls $(P<0.001)$.

†Younger children had a significantly higher mean CR or UE score compared with older children $(P<0.01)$

$(r=-0 \cdot 21, P<0 \cdot 01)$. No significant correlations for $\mathrm{EE}$ were found. Younger children scored higher on CR and $\operatorname{UE}\left(F_{(1,439)}=4 \cdot 56, P<0 \cdot 05, \eta^{2}=0 \cdot 01 ;\right.$ and $F_{(1,437)}=34 \cdot 61$, $P<0.001, \eta^{2}=0.07$, respectively). Boys reported higher UE scores $\left(F_{(1,437)}=7 \cdot 07, P<0 \cdot 01, \eta^{2}=0 \cdot 02\right)$. No differences by age and sex were found for EE (see Table 2 ).

\section{CTFEQr17, body weight and BMI}

After controlling for age, CR was found to correlate positively with weight $(r=0.21, P<0.05)$, BMI $(r=0.25$, $P<0.01)$ and BMI percentile $(r=0.21, P<0.05)$ for girls only. No other associations were found.

Table 3 presents the participant characteristics by CTFEQr17 group. ANCOVA revealed that those with a HCR had a significantly higher weight $\left(F_{(1,247)}=8 \cdot 29, P<0 \cdot 01\right.$, $\left.\eta^{2}=0.04\right)$, BMI $\left(F_{(1,247)}=12 \cdot 35, P=0.001, \eta^{2}=0.05\right)$ and BMI percentile $\left(F_{(1,246)}=8 \cdot 41, P<0 \cdot 01, \eta^{2}=0 \cdot 04\right)$, regardless of sex. No significant differences between UE and EE groups and anthropometric measures were evident. Age was a significant covariate throughout these analyses $(P<0 \cdot 01)$.

\section{CTFEQr17, food and taste preferences}

Younger children were found to have a higher food preference for all categories; high-carbohydrate foods $(r=-0.33, \quad P<0.001), \quad$ high-fat foods $\quad(r=-0.24$, $P<0.001)$ and low-energy foods $(r=-0 \cdot 23, P<0 \cdot 001)$. This was particularly so for younger girls compared with boys. BMI correlated negatively with high-carbohydrate food preference $(r=-0 \cdot 24, P<0 \cdot 001)$. This association was found to be stronger in boys. No association between BMI percentile and food preference was found.

Partial correlations showed that UE was positively related to preferences for high-fat foods $(r=0.26$, $P<0.001)$, high-protein foods $(r=0.27, P<0.001)$ and high-carbohydrate foods $(r=0.23, P<0.001)$. The relationships between UE and food preferences were found to be stronger in girls. Also, for EE significant relationships existed only for girls, for high-carbohydrate foods $(r=0 \cdot 25, P<0 \cdot 01)$, high-protein foods $(r=0 \cdot 22, P<0.05)$ and high-fat foods $(r=0 \cdot 21, P<0 \cdot 05)$. No significant correlations between CR and food preferences were found.

Food preferences were found to differ significantly between the CTFEQr17 groups (see Table 4). ANCOVA revealed for high-protein foods that the HUE group had a higher preference compared with the LUE group $\left(F_{(1,241)}=17 \cdot 74, \quad P<0 \cdot 001, \eta^{2}=0 \cdot 07\right)$. Boys consistently showed a higher protein preference, regardless of CR, UE and EE groups $\left(F_{(1,242)}=20 \cdot 09, P<0.001, \eta^{2}=0 \cdot 08 ; F_{(1,241)}=14.98\right.$, $P<0.001, \eta^{2}=0.06$; and $F_{(1,242)}=18.28, P<0.001, \eta^{2}=0.07$, respectively). Both the HUE and HEE groups reported a greater preference for high-fat foods $\left(F_{(1,241)}=16 \cdot 79\right.$, $P<0.001, \quad \eta^{2}=0.07$; and $F_{(1,242)}=5.45, \quad P<0.05, \quad \eta^{2}=0.02$, respectively) and high-carbohydrate foods $\left(F_{(1,241)}=16 \cdot 85\right.$, $P<0.001, \quad \eta^{2}=0.07 ;$ and $F_{(1,242)}=4.63, \quad P<0.05, \quad \eta^{2}=0.02$, respectively). No differences were found for preference for low-energy foods. Age was a significant covariate throughout the analyses $(P<0 \cdot 001)$.

In terms of taste preference, younger children had a higher preference across most categories; LFSA $(r=-0 \cdot 25$, $P<0.001)$, LFSW $(r=-0.23, \quad P<0.001)$ and HFSW $(r=-0.26, P<0 \cdot 001)$. Taste preference was found to correlate more strongly for girls compared with boys. However, BMI was only found to correlate with taste preference in boys for HFSW foods $(r=-0 \cdot 24, P<0 \cdot 01)$.

Partial correlations revealed that UE was positively correlated with preference for HFSA $(r=0.31, P<0 \cdot 001)$ and HFSW foods $(r=0.27, P<0 \cdot 001)$. When examined by sex, taste preference associations were stronger in girls: UE and EE with HFSW $(r=0.38, P<0.001$; and $r=0.25$, $P<0 \cdot 01$, respectively) and HFSA foods $(r=0 \cdot 34, P<0 \cdot 001$; and $r=0 \cdot 20, P<0 \cdot 05$, respectively), and UE with LFSA foods $(r=0 \cdot 25, P<0 \cdot 01)$. No taste preference associations were found with $\mathrm{CR}$.

The CTFEQr17 groups also discriminated between taste preferences (see Table 4). ANCOVA revealed that, irrespective of CR, UE or EE group, boys consistently had higher preferences for LFSA foods $\left(F_{(1,241)}=6 \cdot 50, P<0 \cdot 05\right.$, $\eta^{2}=0.03 ; \quad F_{(1,240)}=4.23, \quad P<0.05, \quad \eta^{2}=0.02 ; \quad$ and $F_{(1,241)}=6 \cdot 02, P<0 \cdot 05, \eta^{2}=0 \cdot 02$, respectively) and HFSA foods $\left(F_{(1,242)}=9.44, \quad P<0.01, \quad \eta^{2}=0.04 ; \quad F_{(1,241)}=6.70\right.$, $P=0.01, \eta^{2}=0.02 ;$ and $F_{(1,242)}=8.71, P<0.01, \eta^{2}=0.04$, respectively). The HUE group had a higher preference for LFSA foods $\left(F_{(1,240)}=9 \cdot 24, P<0 \cdot 01, \eta^{2}=0.04\right)$. In addition, those with a HUE and HEE had a higher preference for HFSA foods $\left(F_{(1,240)}=18.66, \quad P<0.001, \quad \eta^{2}=0.09\right.$; and $F_{(1,242)}=3.62, \quad P=0.058, \quad \eta^{2}=0.02, \quad$ respectively) and 
HFSW foods $\left(F_{(1,241)}=18.60, \quad P<0 \cdot 001, \eta^{2}=0.07 ;\right.$ and $F_{(1,242)}=8.45, P<0.01, \eta^{2}=0.03$, respectively). Age was a significant covariate throughout the analyses $(P<0 \cdot 001)$.

\section{Discussion}

The main aim of the present work was to propose a validated adaptation of the TFEQr21 among children and adolescents. According to our results, the proposed CTFEQr17 successfully assesses psychological eating behaviour traits in children and adolescents, and shows associations with body weight, BMI and food preferences. These findings are supported by qualitative data showing that the children had a good understanding of the CTFEQr17 items, confirming the strength and usefulness of this tool.

\section{CTFEQr17 and anthropometric measures}

A high CR score was shown to be associated with a higher body weight, BMI and BMI percentile in girls. This finding supports previous work with adolescents by van Strein et $a l .{ }^{(8)}$, Snoek et al. ${ }^{(9)}$ and Martín-García et al. ${ }^{(19)}$. Evidence also supports a stronger association between adverse weight regulation and dietary restraint in girls compared with boys ${ }^{(22)}$. These seemingly counter-intuitive findings are explained well with the goal conflict theory ${ }^{(23)}$. This theory posits that weight regulation issues are a result of the conflict between the goal of weight control and the goal of eating enjoyment; the hedonic expectation of food often undermines the goal of weight control ${ }^{(24)}$. In the current obesogenic environment, replete with palatable foods, the goal of eating enjoyment is more often primed, requiring a higher cognitive effort to maintain the goal of weight control $^{(23)}$. Such cognitive effort can easily become more difficult to maintain when other issues (e.g. emotions, work) reduce cognitive capacity available, resulting in the goal of eating enjoyment becoming much easier to access ${ }^{(23)}$. As a consequence, a less healthy eating pattern can occur, leading to a susceptibility to weight gain ${ }^{(25)}$.

Although the goal conflict theory supports our results, conflicting evidence exists, as restrained eating has also been associated with lower food intake and better weight regulation $^{(26-28)}$. This suggests that some individuals are better able to maintain their weight control goal in comparison to their eating enjoyment goal. Thus, the relationship between CR and weight is complex, and CR likely interacts with other eating behaviour traits (e.g. disinhibition) to produce differing influences upon body weight ${ }^{(6,29)}$. That CR was associated with a higher weight and higher BMI in this child and adolescent sample supports a large body of adolescent and adult data, suggesting the CTFEQr17 has successfully measured this psychological construct.

Both UE and EE were found not to be related to anthropometric measures. This lack of association has also been found in adults ${ }^{(13)}$. However, there is evidence suggesting that $\mathrm{EE}^{(30)}, \mathrm{UE}^{(19,31)}$ or both $\mathrm{UE}$ and $\mathrm{EE}^{(32,33)}$ are associated with higher weight and BMI in adolescents and adults. 
Table 4 Food and taste preferences, by groups of low/high factor scores on the new Child Three-Factor Eating Questionnaire (CTFEQr17) and sex, among a sample of 433 children and adolescents (230 boys) recruited from primary and secondary schools in West Yorkshire and Lancashire, UK, 2016-2017

\begin{tabular}{|c|c|c|c|c|c|c|c|c|c|c|c|c|c|c|c|c|c|c|c|}
\hline & & \multicolumn{6}{|c|}{$\mathrm{CR}$} & \multicolumn{6}{|c|}{ UE } & \multicolumn{6}{|c|}{ EE } \\
\hline & & \multicolumn{2}{|c|}{ Low } & \multicolumn{2}{|c|}{ High } & \multicolumn{2}{|c|}{$\begin{array}{l}\text { Mean score by } \\
\text { sex }\end{array}$} & \multicolumn{2}{|c|}{ Low } & \multicolumn{2}{|c|}{ High } & \multicolumn{2}{|c|}{$\begin{array}{c}\text { Mean score by } \\
\text { sex }\end{array}$} & \multicolumn{2}{|c|}{ Low } & \multicolumn{2}{|c|}{ High } & \multicolumn{2}{|c|}{$\begin{array}{c}\text { Mean score by } \\
\text { sex }\end{array}$} \\
\hline & & Mean & SD & Mean & SD & Mean & SD & Mean & SD & Mean & SD & Mean & SD & Mean & $\mathrm{SD}$ & Mean & SD & Mean & SD \\
\hline \multirow[t]{3}{*}{ High-protein food preference } & Boys & 2.91 & 2.96 & 2.42 & 2.25 & 2.59 & $2 \cdot 52$ & 1.82 & 1.98 & 3.09 & $2 \cdot 71$ & 2.59 & 2.52 & 2.59 & 2.92 & 2.59 & 2.23 & 2.59 & 2.52 \\
\hline & Girls & 1.19 & 1.66 & 1.56 & 1.82 & $1.40^{*}$ & 1.76 & 0.79 & 1.03 & 2.03 & $2 \cdot 11$ & $1.40^{*}$ & 1.77 & 0.93 & 1.40 & 1.83 & 1.95 & $1.40^{*}$ & 1.76 \\
\hline & Mean CTFEQr17 score & 1.97 & 2.48 & 2.03 & $2 \cdot 11$ & - & - & 1.25 & 1.61 & $2.63 \dagger$ & $2 \cdot 52$ & - & - & $1 \cdot 71$ & $2 \cdot 38$ & $2 \cdot 24$ & $2 \cdot 13$ & - & - \\
\hline \multirow{3}{*}{ High-carbohydrate food preference } & Boys & 3.27 & $2 \cdot 23$ & 3.24 & $2 \cdot 17$ & 3.25 & $2 \cdot 19$ & 2.50 & 2.09 & 3.74 & $2 \cdot 12$ & 3.25 & $2 \cdot 19$ & 3.29 & $2 \cdot 19$ & 3.22 & $2 \cdot 20$ & 3.25 & $2 \cdot 19$ \\
\hline & Girls & 2.36 & 1.96 & 3.35 & 2.02 & 2.92 & 2.05 & $2 \cdot 21$ & 1.93 & 3.68 & 1.92 & 2.93 & 2.05 & $2 \cdot 28$ & $2 \cdot 13$ & 3.51 & 1.80 & 2.92 & 2.05 \\
\hline & Mean CTFEQr17 score & 2.77 & $2 \cdot 13$ & 3.29 & $2 \cdot 11$ & - & - & $2 \cdot 34$ & 2.00 & $3.71 \dagger$ & 2.02 & - & - & $2 \cdot 75$ & $2 \cdot 21$ & $3.35 \dagger$ & 2.03 & - & - \\
\hline \multirow{3}{*}{ High-fat food preference } & Boys & 3.45 & $2 \cdot 19$ & 3.51 & 2.43 & 3.50 & 2.34 & 2.86 & 2.63 & 3.90 & 2.05 & 3.50 & 2.34 & 3.29 & 2.26 & 3.63 & $2 \cdot 40$ & 3.50 & 2.34 \\
\hline & Girls & 3.64 & 2.47 & 3.51 & 1.74 & 3.57 & 2.08 & 2.77 & 1.38 & 4.42 & 2.35 & 3.58 & 2.09 & 3.05 & 1.61 & 4.05 & $2 \cdot 36$ & 3.57 & 2.08 \\
\hline & Mean CTFEQr17 score & 3.56 & $2 \cdot 34$ & 3.51 & $2 \cdot 14$ & - & - & $2 \cdot 81$ & 2.03 & $4.13 \dagger$ & $2 \cdot 20$ & - & - & $3 \cdot 17$ & 1.93 & $3.82 \dagger$ & $2 \cdot 38$ & - & - \\
\hline \multirow[t]{3}{*}{ Low-energy food preference } & Boys & 3.25 & 2.31 & 3.01 & 1.82 & 3.10 & $2 \cdot 15$ & 3.28 & 2.05 & 2.97 & 1.97 & $3 \cdot 10$ & 2.00 & 3.45 & 2.35 & 2.85 & 1.70 & $3 \cdot 10$ & 2.00 \\
\hline & Girls & 2.49 & $2 \cdot 15$ & 3.59 & 2.01 & 3.11 & $2 \cdot 14$ & $2 \cdot 69$ & 1.92 & 3.56 & $2 \cdot 28$ & 3.12 & $2 \cdot 14$ & $2 \cdot 67$ & 1.88 & 3.51 & $2 \cdot 29$ & 3.11 & $2 \cdot 14$ \\
\hline & Mean CTFEQr17 score & 2.84 & $2 \cdot 25$ & 3.27 & 1.92 & - & - & 2.96 & 1.99 & 3.23 & $2 \cdot 13$ & - & - & 3.04 & $2 \cdot 13$ & 3.15 & 2.01 & - & - \\
\hline \multirow{3}{*}{ LFSA taste preference } & Boys & 0.35 & 0.30 & 0.32 & 0.20 & 0.33 & 0.24 & 0.28 & 0.22 & 0.36 & 0.25 & 0.33 & 0.24 & 0.35 & 0.27 & 0.32 & 0.22 & 0.33 & 0.24 \\
\hline & Girls & 0.22 & 0.21 & 0.30 & 0.20 & $0.26^{*}$ & 0.21 & 0.19 & 0.17 & 0.34 & 0.22 & $0.26^{*}$ & 0.21 & 0.20 & 0.18 & 0.32 & 0.21 & $0.26^{*}$ & 0.21 \\
\hline & Mean CTFEQr17 score & 0.28 & 0.26 & 0.31 & 0.20 & - & - & 0.23 & 0.20 & $0.35 \dagger$ & 0.24 & - & - & 0.27 & 0.24 & 0.32 & 0.22 & - & - \\
\hline \multirow{3}{*}{ LFSW taste preference } & Boys & 0.48 & 0.33 & 0.48 & 0.30 & 0.48 & 0.31 & 0.48 & 0.31 & 0.48 & 0.32 & 0.48 & 0.31 & 0.54 & 0.35 & 0.44 & 0.28 & 0.48 & 0.31 \\
\hline & Girls & 0.41 & 0.28 & 0.59 & 0.28 & 0.51 & 0.29 & 0.48 & 0.30 & 0.55 & 0.29 & 0.51 & 0.29 & 0.47 & 0.29 & 0.55 & 0.29 & 0.51 & 0.29 \\
\hline & Mean CTFEQr17 score & 0.44 & 0.31 & 0.53 & 0.30 & - & - & 0.48 & 0.30 & 0.51 & 0.31 & - & - & 0.50 & 0.32 & 0.49 & 0.29 & - & - \\
\hline \multirow{3}{*}{ HFSA taste preference } & Boys & 0.36 & 0.25 & 0.34 & 0.27 & 0.35 & 0.26 & 0.25 & 0.24 & 0.41 & 0.26 & 0.35 & 0.26 & 0.34 & 0.27 & 0.35 & 0.26 & 0.35 & 0.26 \\
\hline & Girls & 0.21 & 0.22 & 0.28 & 0.21 & $0.25^{*}$ & 0.22 & 0.17 & 0.16 & 0.34 & 0.23 & $0.25^{*}$ & 0.22 & 0.20 & 0.19 & 0.30 & 0.23 & $0.25^{*}$ & 0.22 \\
\hline & Mean CTFEQr17 score & 0.28 & 0.24 & 0.31 & 0.25 & - & - & 0.21 & 0.21 & $0.38 \dagger$ & 0.25 & - & - & 0.26 & 0.24 & 0.33 & 0.25 & - & - \\
\hline \multirow{3}{*}{ HFSW preference } & Boys & 0.49 & 0.30 & 0.46 & 0.34 & 0.47 & 0.33 & 0.38 & 0.37 & 0.53 & 0.28 & 0.47 & 0.33 & 0.44 & 0.32 & 0.49 & 0.34 & 0.47 & 0.33 \\
\hline & Girls & 0.47 & 0.39 & 0.47 & 0.32 & 0.47 & 0.32 & 0.35 & 0.21 & 0.60 & 0.37 & 0.47 & 0.37 & 0.37 & 0.25 & 0.56 & 0.36 & 0.47 & 0.32 \\
\hline & Mean CTFEQr17 score & 0.48 & 0.35 & 0.46 & 0.31 & - & - & 0.36 & 0.29 & $0.56 \dagger$ & 0.32 & - & - & 0.40 & 0.28 & $0.52 \dagger$ & 0.35 & - & - \\
\hline
\end{tabular}

CR, cognitive restraint; UE, uncontrolled eating; EE, emotional eating; LFSA, low-fat savoury; HFSA, high-fat savoury; LFSW, low-fat sweet; HFSW, high-fat sweet.

${ }^{*}$ Girls had a significantly different mean food/taste preference compared with boys $(P<0.05$ to $P<0.001)$.
†Mean food/taste preference in the high CR, UE or EE group was significantly different compared with that in the low CR, UE or EE group $(P<0.05$ to $P<0.001)$. 
Where relationships have been found in adolescents ${ }^{(19)}$, the study sample consisted of overweight/obese and lean groups of children/adolescents. In the current study, children and adolescents were sampled from schools and not selected based on their weight status, thus having a lower proportion of overweight and obese participants. This could explain why associations with UE and EE were not found. In addition, where relationships have been found in adult samples, this has, at least partially, been attributed to food choice, whereby those with a higher UE and EE have a less healthful diet, higher energy intake and higher snack intake $^{(31,33)}$ and partake in less physical activity ${ }^{(33)}$. This suggests that the food preferences of UE and EE can impact adversely upon weight status.

\section{CTFEQr17, food and taste preferences}

Higher preferences for HFSA, HFSW, high-carbohydrate and high-fat foods were evident in those children who were characterized by higher UE and EE scores; this relationship was particularly strong in girls. This taste preference pattern reflects evidence from adult populations, which have shown a higher preference for high-fat foods in UE and EE adults ${ }^{(34)}$. A preference for HFSW foods in individuals with a HEE has also been found to be particularly strong in women compared with men ${ }^{(34)}$. This indicates that the taste preferences, and associated sex differences, found in adults are also found in children and adolescents, suggesting these preferences begin in childhood and persist into adulthood. Furthermore, UE and EE are characterized by eating in response to the palatability of food, eating opportunistically and eating in response to negative affect. Individuals with a HUE and HEE report a higher preference for high-fat (savoury and sweet) and high-carbohydrate foods ${ }^{(34,35)}$. These foods typically reflect highly palatable, energy-dense foods (e.g. crisps, sausage roll, biscuits, cakes). Due to their macronutrient content, these foods have a relatively low satiating ability ${ }^{(36)}$ and eating them can result in passive overconsumption $^{(37)}$, increasing vulnerability to future weight gain $^{(38)}$. Indeed, this is reflected in adult data where UE and $\mathrm{EE}$ are related to higher body weight ${ }^{(32,33)}$.

Independently of CTFEQr17 scores, males were found to have a higher preference for high-protein, HFSA and LFSA foods. This pattern has previously been reported in children and adolescents ${ }^{(39)}$ and adults ${ }^{(40)}$. In addition, younger children also reported higher food preferences than older children, regardless of gender; this has also been previously reported ${ }^{(39)}$. Interestingly, food and taste preferences were more strongly related to psychological factors of the CTFEQr17 in girls than boys, whereas food preference was more strongly associated with anthropometric measures in boys. This is despite no difference in sex being reported for CR and EE, and boys scoring higher on the UE scale. Existing evidence purports that females tend to score more highly on CR, UE and EE in adolescents $^{(41)}$, on EE in adults ${ }^{(14,42)}$ and on CR in adults ${ }^{(43,44)}$.
Thus, females are reporting a higher influence of psychological eating behaviour traits over their eating behaviour. The reason for this sex difference is unclear and needs to be further elucidated.

\section{Strengths and limitations}

A strength of the present study is that the CTFEQr17 was both statistically and qualitatively verified as valid. The development of the CTFEQr17 involved creating accessible items by using the children's/adolescent's own phraseology ascertained from interviews. This produced a questionnaire that was highly understandable for children and adolescents. However, although associations between the CTFEQr17 and food and taste preferences were found, measurement of actual food intake was not carried out. Food preferences and the relationship between 'liking' and 'wanting' of foods have been found to be related to food intake $^{(45)}$ as well as associated with TFEQ factors in adults $^{(46)}$, thus an examination of this relationship in children and adolescents would be beneficial. A further limitation of the study is that body composition was not assessed, with research suggesting measurement of actual body composition is more accurate in determining relevant relationships than $\mathrm{BMI}^{(47,48)}$. Research by Martín-García et al. ${ }^{(19)}$ also found an association between fat mass and CR in children and adolescents, therefore further exploration of this is of interest. Furthermore, although our sample size was adequate for the intended analysis, there was a larger proportion of secondary-school children; further consideration of the CTFEQr17 in primary-school children would be interesting. However, our sample did reflect that which was used to validate the Spanish TFEQr21C ${ }^{(19)}$.

\section{Conclusion}

The CTFEQr17 shows good internal consistency and is suitable for use in children and adolescents. The factor of CR was found to be associated with higher body weight, BMI and BMI percentile, thus those children who were larger showed more restrictive eating behaviours. Both UE and EE were associated with a higher preference for HFSA and HFSW foods, which is consistent with adult data and demonstrates that children with these eating behaviour traits have less healthy food preferences. Furthermore, a sex difference in the relationships between CTFEQr17 factors, anthropometric measurements and food preferences was apparent, whereby a stronger relationship was observed in girls. Collectively, the CTFEQr17 appears to be a valid and suitable tool to measure eating behaviour traits in children and adolescents.

\section{Acknowledgements}

Acknowledgements: The authors would like to thank the schools that participated in this study (Falinge Park High 
School, South Craven Secondary School, Otley All Saints Church-of-England Primary School, Sutton Church-ofEngland Primary School). They also thank the research assistants for helping with data collection (Matt Haigh, Amirah Akhtar, Naila Anjum, Alya Ponsford, Maria Rehmat, Sara Aslam, Anam Ayaz-Shah, Victoria Marshall, Paulina Jozwiak). Financial support: This research received no specific grant from any funding agency in the public, commercial or not-for-profit sectors. Conflict of interest: The authors have no financial relationships relevant to this article or conflicts of interest to disclose. Authorship: E.B. designed the study, collected and analysed the data, and wrote the paper; D.T., J.-P.C., V.D., J.E.B. and N.A.K. advised on the design and contributed to the write-up. Ethics of buman subject participation: This study was conducted according to the guidelines laid down in the Declaration of Helsinki and all procedures involving human subjects were approved by the University of Bradford Ethics Committee. Verbal informed consent was obtained from all subjects. Verbal consent was witnessed and formally recorded.

\section{References}

1. GBD 2015 Obesity Collaborators (2017) Health effects of overweight and obesity in 195 countries over 25 years. $N$ Eng J Med 377, 13-27.

2. Ogden CL, Lamb MM, Carroll MD et al. (2010) Obesity and socioeconomic status in children and adolescents: United States, 2005-2008. NCHS Data Brief issue 51, 1-8.

3. Cattaneo A, Monasta L, Stamatakis E et al. (2010) Overweight and obesity in infants and pre-school children in the European Union: a review of existing data. Obes Rev 11, 389-398.

4. Swinburn B, Egger G \& Raza F (1999) Dissecting obesogenic environments: the development and application of a framework for identifying and prioritizing environmental interventions for obesity. Prev Med 29, 563-570.

5. Swinburn BA, Sacks G, Hall KD et al. (2011) The global obesity pandemic: shaped by global drivers and local environments. Lancet 378, 804-814.

6. Gallant AR, Tremblay A, Pérusse L et al. (2010) The ThreeFactor Eating Questionnaire and BMI in adolescents: results from the Québec Family Study. Br J Nutr 104, 1074-1079.

7. Chaput JP, Leblanc C, Pérusse L et al. (2009) Risk factors for adult overweight and obesity in the Quebec Family Study: have we been barking up the wrong tree? Obesity (Silver Spring) 17, 1964-1970.

8. van Strien T, Herman CP \& Verheijden MW (2012) Eating style, overeating and weight gain. A prospective 2-year follow-up study in a representative Dutch sample. Appetite 59, 782-789.

9. Snoek HM, Engels RC, van Strien T et al. (2013) Emotional, external and restrained eating behaviour and BMI trajectories in adolescence. Appetite 67, 81-87.

10. Polivy J \& Herman CP (1976) Effects of alcohol on eating behavior: influence of mood and perceived intoxication. J Abnorm Psychol 85, 601-606.

11. Meyer JE \& Pudel VE (1977) Experimental feeding in man: a behavioral approach to obesity. Psychosom Med 39, 153-157.

12. Bryant EJ, King NA \& Blundell JE (2008) Disinhibition: its effect on appetite and weight regulation. Obes Rev 9, 409-419.

13. Cappelleri JC, Bushmakin AG, Gerber RA et al. (2009) Psychometric analysis of the Three-Factor Eating
Questionnaire-R21: results from a large diverse sample of obese and non-obese participants. Int J Obes (Lond) 33, 611-620.

14. Karlsson J, Persson LO, Sjöström L et al. (2000) Psychometric properties and factor structure of the Three-Factor Eating Questionnaire (TFEQ) in obese men and women. Results from the Swedish Obese Subjects (SOS) study. Int J Obes Relat Metab Disord 24, 1715-1725.

15. Stunkard AJ \& Messick S (1985) The three-factor eating questionnaire to measure dietary restraint, disinhibition and hunger. J Psychosom Res 29, 71-83.

16. Karakuş SŞ, Yıldırım H \& Büyüköztürk Ş (2016) Adaptation of three factor eating questionnaire (TFEQ-R21) into Turkish culture: a validity and reliability study. TAF Prev Med Bull 15, 229-237.

17. Drapeau V, Depres JP, Bouchard C et al. (2004) Modifications in food-group consumption are related to long-term body-weight changes. Am J Clin Nutr 80, 29-37.

18. de Medeiros ACQ, Yamamoto ME, Pedrosa LFC et al. (2016) The Brazilian version of the three-factor eating questionnaire-R21: psychometric evaluation and scoring pattern. Eat Weight Disord 22, 169-175.

19. Martín-García M, Vila-Maldonado S, Rodríguez-Gómez I et al. (2016) The Spanish version of the Three Factor Eating Questionnaire-R21 for children and adolescents (TFEQ-R21C): psychometric analysis and relationships with body composition and fitness variables. Physiol Behav 165, 350-357.

20. de Onis M, Onyango AW, Borghi E et al. (2007) Development of a WHO growth reference for school-aged children and adolescents. Bull World Health Organ 85, 660-667.

21. Halford JCG, Boyland EJ, Cooper GD et al. (2008) Children's food preferences: effects of weight status, food type, branding and television food advertisements (commercials). Int J Pediatr Obes 3, 31-38.

22. Halberstadt J, van Strien T, de Vet E et al. (2016) The association of eating styles with weight change after an intensive combination lifestyle intervention for children and adolescents with severe obesity. Appetite 99, 82-90.

23. Stroebe W, van Koningsbruggen GM, Papies EK et al. (2013) Why most dieters fail but some succeed: a goal conflict model of eating behavior. Psychol Rev 120, 110-138.

24. Veling H, Aarts H \& Papies EK (2011) Using stop signals to inhibit chronic dieters' responses toward palatable foods. Behav Res Ther 49, 771-780.

25. van Strien T, Herman CP \& Verheijden MW (2014) Dietary restraint and body mass change. A 3-year follow-up study in a representative Dutch sample. Appetite 76, 44-49.

26. Kemps E, Herman CP, Hollitt S et al. (2016) The role of expectations in the effect of food exposure on food intake. Appetite 103, 259-264.

27. Graham A, Gluck ME, Votruba SB et al. (2014) Perseveration augments the effect of cognitive restraint on ad libitum food intake in adults seeking weight loss. Appetite 82, 78-84.

28. Roberts CJ, Campbell IC \& Troop N (2013) Increases in weight during chronic stress are partially associated with a switch in food choice towards increased carbohydrate and saturated fat intake. Eur Eat Disord Rev 22, 77-82.

29. Bryant EJ, Kiezebrink K, King NA et al. (2010) Interaction between disinhibition and restraint: implications for body weight and eating disturbance. Eat Weight Disord 15, e43-e51.

30. Anglé S, Engblom J, Eriksson T et al. (2009) Three factor eating questionnaire R18 as a measure of cognitive restraint, uncontrolled eating and emotional eating in a sample of young Finnish females. Int J Behav Nutr Phys Act 6, 41.

31. de Lauzon B, Roman M, Deschamps V et al. (2004) The Three-Factor Eating Questionnaire R18 is able to distinguish among different eating patterns in the general population. J Nutr 134, 2372-2380.

32. Konttinen H, Haukala A, Sarlio-Lähteenkarva S et al. (2009) Eating styles, self-control and obesity indicators. The 
moderating role of obesity status and dieting history on restrained eating. Appetite 53, 131-134.

33. Green GW, Schembre SM, White AA et al. (2011) Identifying clusters of college students at elevated health risk based on eating and exercise behaviors and psychosocial determinants of body weight. $J$ Am Diet Assoc 111, 394-400.

34. Keskitalo K, Tuorila H, Spector TD et al. (2008) The three factor eating questionnaire, body mass index, and responses to sweet and salty fatty foods: a twin study of genetic and environmental associations. Am J Clin Nutr 88, 263-271.

35. Camilleri GM, Méjean C, Kesse-Guyot E et al. (2014) The associations between emotional eating and consumption of energy-dense snack foods are modified by sex and depressive symptomology. J Nutr 144, 1264-1273.

36. Gerstein DE, Woodward-Lopez G, Evans AE et al. (2004) Clarifying concepts about macronutrients' effects on satiation and satiety. J Am Diet Assoc 104, 1151-1153.

37. Westerterp KR (2006) Perception, passive overfeeding and energy metabolism. Physiol Behav 89, 62-65.

38. Blundell JE \& MacDiarmid JI (1997) Fat as a risk factor for overconsumption: satiation, satiety and patterns of eating. J Am Diet Assoc 97, 7 Suppl, S63-S69.

39. Caine-Bish NL \& Scheule B (2009) Gender differences in food preferences of school-aged children and adolescents. $J$ Sch Health 79, 532-540.

40. Arganini C, Saba A, Comitato F et al. (2012) Gender differences in food choice and dietary intake in modern western societies. In Public Health - Social and Behavioral Health, Chapter 4 [J Maddock, editor]. InTech: Open Science; available at http://www.intechopen.com/books/publichealth-social-and-behavioral-health/gender-differences-infoodchoice-and-dietary-intake-in-modern-western-societies

41. Vagstrand K, Linne Y, Karlsson J et al. (2009) Correlates of soft drink and fruit juice consumption among Swedish adolescents. Br J Nutr 101, 1541-1548.

42. Péneau S, Ménard E, Méjean C et al. (2013) Sex and dieting modify the association between emotional eating and weight status. Am J Clin Nutr 97, 1307-1313.

43. Hainer V, Kanesova M, Bellisle F et al. (2006) The eating inventory, body adiposity and prevention of diseases in a quota of Czech adults. Int J Obes (Lond) 30, 830-836.

44. Provencher V, Drapeau V, Tremblay A et al. (2003) Eating behaviors and indices of body composition in men and women from the Québec family study. Obes Res 11, 783-792.

45. Finlayson G \& Dalton M (2012) Current progress in the assessment of 'liking' vs. 'wanting' food in human appetite. Comment on "You say it's liking, I say it's wanting...". On the difficulty of disentangling food reward in man'. Appetite $\mathbf{5 8}$, 373-378.

46. Finlayson G, Bordes I, Griffioen-Roose S et al. (2012) Susceptibility to overeating affects the impact of savory or sweet drinks on satiation, reward, and food intake in nonobese women. Am Soc Nutr 142, 125-130.

47. Prentice AM \& Jebb SA (2001) Beyond body mass index. Obes Rev 2, 141-147.

48. Wells JCK, Coward WA, Cole TJ et al. (2002) The contribution of fat and fat-free tissue to body mass index in contemporary children and the reference child. Int J Obes Relat Metab Disord 26, 1323-1329.

\section{Appendix}

\section{The Child Three-Factor Eating Questionnaire (CTFEQr17)}

The items have been coded as in the original TFEQr21 ${ }^{(13)}$.
1. I eat small portions of food to help control my weight. Totally true $(=4)$; mostly true $(=3)$; mostly false $(=2)$; totally false $(=1)$.

2. I start to eat when I feel worried. Totally true $(=4)$; mostly true $(=3)$; mostly false $(=2)$; totally false $(=1)$.

3. Sometimes when I start eating, it seems I can't stop. Totally true $(=4)$; mostly true $(=3)$; mostly false $(=2)$; totally false $(=1)$.

4. When I am sad, I usually eat too much. Totally true $(=4)$; mostly true $(=3)$; mostly false $(=2)$; totally false $(=1)$.

5. I don't eat some kinds of food because they can make me fat. Totally true $(=4)$; mostly true $(=3)$; mostly false $(=2)$; totally false $(=1)$.

6. When I am next to someone who is eating, I also feel like eating. Totally true $(=4)$; mostly true $(=3)$; mostly false $(=2)$; totally false $(=1)$.

7. When I feel angry, I need to eat. Totally true $(=4)$; mostly true $(=3)$; mostly false $(=2)$; totally false $(=1)$.

8. I often get so hungry that I feel like I could eat loads of food without getting full. Totally true $(=4)$; mostly true $(=3)$; mostly false $(=2)$; totally false $(=1)$.

9. When I am hungry, I feel like to have to eat all of the food on my plate in one go, without stopping. Totally true $(=4)$; mostly true $(=3)$; mostly false $(=2)$; totally false $(=1)$.

10. When I feel lonely, I make myself feel better by eating. Totally true $(=4)$; mostly true $(=3)$; mostly false $(=2)$; totally false $(=1)$.

11. I eat less than I want at meal times to stop myself putting on weight. Totally true $(=4)$; mostly true $(=3)$; mostly false $(=2)$; totally false $(=1)$.

12. When I smell or see my favourite food, I find it hard to stop myself from eating it, even if I've just finished a meal. Totally true $(=4)$; mostly true $(=3)$; mostly false $(=2)$; totally false $(=1)$.

13. I'm always hungry enough to eat at any time. Totally true $(=4)$; mostly true $(=3)$; mostly false $(=2)$; totally false $(=1)$.

14. If I feel nervous, I try to calm myself down by eating. Totally true $(=4)$; mostly true $(=3)$; mostly false $(=2)$; totally false $(=1)$.

15. When I see something that looks delicious, I get so hungry that I have to eat it right away. Totally true $(=4)$; mostly true $(=3)$; mostly false $(=2)$; totally false $(=1)$.

16. When I feel really upset, I want to eat. Totally true $(=4)$; mostly true $(=3)$; mostly false $(=2)$; totally false $(=1)$.

17. How often do you feel hungry? Only at mealtimes $(=1)$; sometimes between meals $(=2)$; often between meals $(=3)$; almost always $(=4)$. 